\title{
Dealers of Peaches and Lemons: How Can Used Car Dealers Use Trusted Car Data to Create Value?
}

\author{
Joachim Baumann \\ University of Zurich \\ joachim.baumann@uzh.ch
}

\author{
Liudmila Zavolokina \\ University of Zurich \\ zavolokina@ifi.uzh.ch
}

\author{
Gerhard Schwabe \\ University of Zurich \\ schwabe@ifi.uzh.ch
}

\begin{abstract}
The used car market is full of mistrust and uncertainties. Providing a vehicle history with trusted car data increases market transparency but also threatens the market position of used car dealers. But does a vehicle history also provide opportunities for them? Based on expert interviews, we propose three design principles addressing current problems. The evaluation results of prototypes - which are based on these principles - indicate that they could improve the current market situation by easing data access, increasing the efficiency of sales related processes, and by expanding the competences of used car dealers. This paper is one of only few papers analyzing the current situation of used car dealers in the light of emerging new technologies. It indicates that used car dealers do not necessarily become disintermediated by the provision of trusted car data but rather have opportunities to reinvent themselves.
\end{abstract}

\section{Introduction}

Mistrust and uncertainty are omnipresent in automobile markets all over the world [1]. In particular, the used car market suffers from the negative influence of the lack of trust between buyers and sellers. Nobel laureate George Akerlof [2] described the market inefficiencies that arise in a market with information asymmetries. The quality uncertainty of the buyers leads to a situation where "bad cars" (lemons) drive out the "good cars" (peaches). This long-standing adverse selection problem can be addressed by providing full vehicle history. However, it is important to make sure that the quality of the data is high to make it trusted. Today, such trusted data can be provided by car manufacturers, which collect and store these data in their internal systems. Different researchers successfully addressed the problem of adverse selection in the used car market by introducing a trusted vehicle history [3], [4]. They argue that using trusted car data has the potential to act as an enabler of trusted data, makes the market more transparent for the buyers and therefore leads to fewer fraudulent used car sales. However, just looking at the buyers' perspective, without considering the sellers' intentions, does not necessarily lead to a feasible solution that ameliorates the used car market in the long term. To our knowledge, the current situation of used car dealers in the light of emerging new technologies has not been widely examined. In this regard, our paper takes an exploratory approach and strives to empirically identify the influence of trusted car data on the used car dealer's value creation. Accordingly, we raise the following research question:

RQ: How can used car dealers use trusted car data to create value?

Initially, we identify sales-related problems that used car dealers are currently facing and, in a second step, we analyze how their sales processes can be improved. Used car dealers are important actors in the car market and many private sellers end up selling their car to a used car dealer [5]. We propose design principles for value creation that is enabled by trusted data. Further, we provide evidence that the usage of trusted car data enables used car dealers to strengthen their advisory role, to increase the efficiency of their offering and to increase the quality of their service offering.

\section{Related Work}

\subsection{Used Car Market}

In most countries, the used car business plays an important role for the automotive market [6]. Typically, used car sales contribute significantly to a car dealership's revenues, and other branches of a car dealership are directly or indirectly influenced by used car sales [7]. From the buyers' perspective, the purchase of a used car is something that is usually well-considered. It is a lengthy buying decision and it represents a major economic burden for the buyer [8]. Still, ordinary buyers do not know a lot about the technical details of a car and therefore often buy a pig in a poke. Akerlof [2] describes this situation as a consequence of the information asymmetries between buyers and sellers. The power relations are unbalanced as sellers have much more bargaining power since they know the quality of their own cars [9]. Buyers on the other hand can observe only the average quality of a car sold at a specific price and have little 
chance to distinguish lemons from peaches [10]. Honest sellers are not able to prove the good quality of their cars and buyers fear being fooled by dishonest sellers [2]. This adverse selection problem can lead to an inefficient market where peaches are sold for the price of an average quality car and thus bad cars drive good cars out of the market, resulting in a lower average quality of all cars in the market and a volume of transaction below the socially optimal level [2], [10]-[12]. Currently, the used car markets in Western European countries are far from being perfect. A consumer study found that the automotive market is among the top three least trusted markets in Germany [13] - along with banks/insurances and the telecommunications industry. Another study, conducted by the European Commission [14], reported that low market-specific consumer knowledge, low trust in car sellers and bad warranties are three of the main problems. This market situation can partially be explained by the fact that car salespeople aim for the buyers to trust them on a personal level rather than relying on facts like a car's quality when negotiating with prospective buyers [5], [15]. According to Diez [5], not all used car dealers have equal access to car data. For example, used car dealers who are in direct contact with a manufacturer profit from access to more car data while others need to rely on the data they find on the Internet. In addition to that, Macaulay [16] and Diez [5] state that used car dealers strive for more efficient processes.

Despite information asymmetries and a lack of trust, used car dealership remains a prosperous business [17]. This might be the result of countermeasures, such as guarantees, brand names, or licensing practices [1], [2]. Besides, used car dealers focus on long-term relationships with their customers [11], strategic sales approaches [8] and quality customer service [5]. Additionally, many dealers act strategically when setting prices to maximize their margin [18]. In the used car business, it is still the car salesperson who has the biggest influence on the margin and hence on the economic success of a used car dealership [18]. From a general viewpoint, a good price strategy alone cannot guarantee economic success. As described more precisely by Diez [5], there are three critical factors for success for used car dealers: An overall clear profiling of the business, optimized processes, and good personnel. Digitalization can help companies to become more efficient and to offer better services to their customers [19]. These technologies should be further analyzed to harness their full potential for the used car market.

\subsection{Trusted Car Data}

In our study, we explore business potentials of 'trusted car data' for used car dealership. According to Bauer et al. [20] the term 'trusted car data' corresponds to securely stored and trustworthy car data, which is in our case achieved by the usage of a blockchain-based application. Prior discussions in the research community proposed that creation of the Internet of trusted data is determined by the following factors: robust digital identity, distributed internet trust authorities, distributed safe computation, and universal access - and blockchain technology is one possible way to address these [21].

We acknowledge that there are several ways for provision and access to trusted car data (such as through car manufacturers, registration authorities, or through a blockchain-based car data storage), and using blockchain technology is only one of these with its opportunities and limits. In our study, we do not focus on the technical aspect of the underlying technology, but rather on the business perspective of availability of trusted data. Even though digitalization in the used car business is not as advanced as it is in other industries [22], experts agree that there are numerous technological opportunities that might disrupt this industry in the near future [23]. Recently, many different blockchain use cases for the car market have been proposed, the most important ones being: optimization of the supply chain process, connected cars and secured vehicle data for used cars [3], [4], [19], [24], [25]. The latter use case has been explored by different researchers: Brousmiche et al. [3] propose a vehicle data and process ledger framework that fosters trust building and data sharing between stakeholders. Zavolokina et al. [4] evaluate the buyers' perspective by providing trusted vehicle data. They found that this approach increases the transparency of the buying process, reduces information asymmetries and is a disincentive to lemon sellers.

Bauer et al. [20] showed that trusted car data creates value for both buyers and sellers of cars and that there is a market potential for trusted data. More specifically, they discovered that - with private persons acting as buyer and seller - a car can be sold at a higher price if trusted car data is available. Therefore, sellers are likely to fear becoming disintermediated due to the provision of trusted car data. However, these studies analyze neither disintermediation potentials nor the potential business value for used car dealers, even though they are important actors in the market for used cars [5].

\section{Methodology}

This study is part of a larger design project, called Car Dossier, that is run by a consortium of organizations from the automotive industry: a car dealer and importer, a car insurance company, a road traffic authority, a car sharing company, a software company, and two universities. Together they intend to improve processes and reduce information asymmetries within the whole car ecosystem. In this study, we present the results from an early 
phase of identification of the business potentials of the Car Dossier for used car dealers. For this, we followed the design science research methodology (DSRM) [26][28]. DSRM is widely accepted in information systems research and aims to find solutions to classes of realworld problems [29]. As an outcome of DSRM, design science researchers create IT artifacts (i.e. design products, design processes). Depending on the design phase, created IT artifacts may vary in terms of their maturity: from proof-of-concept for early stages to proof-of-use in later stages of design research [28]. In the study at hand, we created a proof-of-concept prototype (a clickable mockup of the interface) of an application, implemented on top of the Car Dossier, to be utilized by used car dealers to leverage the potential of trusted car data from the Car Dossier. Proof-of-concept prototypes are appropriate for a better understanding of a problem space and getting early-stage insights into the feasibility of a solution and functionality [28]. As a well-established framework to conduct rigorous design science research, DSRM guides the steps of this study. We follow six activities, as suggested by Peffers et al. [27]: (1) problem identification and motivation, (2) definition of the objectives for a solution, (3) design and development, (4) demonstration, (5) evaluation, and (6) communication.

For (1) problem identification and motivation and (2) definition of the objectives for a solution, multiple methods were applied: a literature review [30], mystery shopping (to address the buyers' perspective) [31] and semistructured expert interviews [32] with used car dealers (to address the dealers' perspective). The focus of the conducted literature review was placed on the current situation of the used car market and trusted car data - as described in section 2. As for mystery shopping, this method was used to better understand the sales conversation, relationships between used car dealers and buyers. Mystery Shopping is a method where someone acts as a normal private customer to in reality observe the process and the behavior of the involved persons - in our case the used car dealers [31]. Ten mystery shopping sessions were conducted in the first quarter of 2019 with used car dealers in Western Europe, the origin of the Car Dossier project. During the mystery shopping sessions, one of the researchers took notes directly after each session to capture their observations. The findings of the mystery shopping were then used to inform the interview guide. The requirements were collected with the subsequent ten semi-structured expert interviews. The goal of these interviews was to find out and better understand aspects that play an important role in the business success of used car dealers. These interviews took place in the first quarter of 2019. Table 1 provides an overview of interview partners. The average duration of an interview was 48 minutes. The interviews were recorded, transcribed and coded [33]. The top-level codes included the following topics: used car market, buyer sales conversation, interaction and trust, used car market of the future, blockchain and Car Dossier, requirements for the application, and integration into business activities. This process helped to formulate problem scenarios and objectives for the solution.

For (3) design and development, three use cases were targeted. The designed prototypes address these three use cases. These prototypes were clickable so that a user could navigate without any additional help from researchers, however, the prototypes contained test data. DSRM suggests that created DSRM artifacts should be evaluated to see if the objectives of the research were achieved. Therefore, in the next steps, (4) demonstration and (5) evaluation were undertaken as follows. The goal of the evaluation was to initially demonstrate if and how well the prototypes performed in a realistic scenario within a specific organizational context [34]. As suggested by Sonnenberg et al. [34], such evaluation may follow "prototyping pattern", i.e. naturalistic and ex-post evaluation, in which researchers specify the artifact design, provide an implementation of the prototype, select 'real users' and a relevant organizational context, observe how the prototype is used, and assess whether or not the set goals of the prototype were achieved during its use.

The prototypes were presented to the possible real users (i.e., used car dealers). The interviews took place between 8 July 2019 and 29 July 2019. Table 1 provides an overview of the participating persons: Of the ten persons who participated in the first-round interviews, eight also participated in the demonstration and evaluation interviews. The average duration of an interview was 54 minutes. At the start of the process, the persons were provided with a laptop, so that they could use the prototypes. After each prototype, the persons were asked to provide feedback in a semi-structured interview and to fill in a short questionnaire, which covered the following categories: process, performance, purpose and enhancement of trust of the IT artifact [35], perceived ease of use [36], perceived usefulness [36], [37], intention to use [37], net promoter score (NPS) [38], and willingness to pay (WTP) for access to such an application [39]. These categories were chosen to evaluate the interviewees' trust in the IT artifacts and the general usability of the IT artifacts. The NPS was chosen in favor of a lengthy questionnaire as it can yield valuable insight into the general value of the IT artifacts. This paper only discusses the most prominent results of the questionnaire. Detailed results of the questionnaire can be found online (https://docs.google.com/document/d/1JwP_3Jw627XImuQcmZNfQ5Q6-rP5IwITHB14FkRGJ2M/exp ort?for$m a t=p d f$ ). In addition, analysis of the semi-structured interviews was used to evaluate the potentials of the designed prototypes for used car dealership. This was done 
by conducting a SWOT analysis [40] for each use case. A SWOT analysis is a helpful framework for strategic planning used to assess strengths, opportunities, weaknesses, and threats of a project or any situation that involves decision-making. Consequently, our approach is to apply this framework to assess business potentials of the introduction of applications, based on the Car Dossier, to used car dealership as a part of our evaluation design. This way, we could assess whether or not the designed prototypes could create value for used car dealers and how. Thus, the questions in the interviews were formulated around four main topics: strengths, opportunities, weaknesses, and threats associated with the introduction of the applications to used car dealership. Similar to the previous round of interviews for problem identification, the interviews were recorded and analyzed. This paper forms the final step, (6) communication, in the DSRM process.

\section{Table 1. Participants of Requirements Collec- tion and Evaluation}

\begin{tabular}{|l|l|c|c|}
\hline Abbreviation & Job & $\begin{array}{l}\text { Requirements } \\
\text { Collection }\end{array}$ & Evaluation \\
\hline I1 & Company Owner & $\checkmark$ & $\checkmark$ \\
\hline I2 & Salesperson & $\checkmark$ & - \\
\hline I3 & Salesperson & $\checkmark$ & $\checkmark$ \\
\hline I4 & Sales Manager & $\checkmark$ & $\checkmark$ \\
\hline I5 & Sales Manager & $\checkmark$ & $\checkmark$ \\
\hline I6 & Salesperson & $\checkmark$ & $\checkmark$ \\
\hline I7 & Company Owner & $\checkmark$ & - \\
\hline I8 & Sales Manager & $\checkmark$ & $\checkmark$ \\
\hline I9 & Company Owner & $\checkmark$ & $\checkmark$ \\
\hline I10 & Sales Manager & $\checkmark$ & $\checkmark$ \\
\hline I11 & Company Owner & - & $\checkmark$ \\
\hline I12 & Sales Manager & - & $\checkmark$ \\
\hline & \multicolumn{2}{|l}{} \\
\hline
\end{tabular}

\section{Problem Formulation and Objectives for the Solution}

The literature review and a detailed analysis of the conducted interviews showed that used car sales are still an important business for car dealerships in Western Europe. More than half of the interviewed used car dealers, including I8, stated that they are not afraid to be replaced in the future. Though, three interviewed used car dealers think that job of used car dealers in the future will be different compared to the situation today. I6 explained that the job of a used car dealer will evolve and that consulting customers will be more important than just selling cars. The analysis further indicated that used car dealers in Western Europe currently face three major problems: (1) insufficient data access for customer advisory services, (2) inefficient processes and (3) bad quality warranties. In our study, we first examine the problems and then infer objectives for the solution [27].

Table 2 lists three problems and for each of them some expert quote examples underneath. Diez [5] explained that not all used car dealers have equal access to car data. In our interviews, insufficient data access for customer advisory services appeared to be one major problem for used car dealers. All ten interviewed used car dealers explained that a good network is necessary to gain access to car data. Still, most of them manifested problems in accessing some data in at least one step of the sales processes. Eight used car dealers stated that accessing the required data for a car is not always possible and normally involves difficulties. On the one hand, used car dealers have problems accessing relevant data within the process of purchasing used cars. This problem was described by company owner I9 along with three other used car dealers. On the other hand, used car dealers struggle to provide trusted data when advising customers. This problem was described by seven of the ten interviewed used car dealers.

Nine of the interviewed used car dealers believe that having access to trusted car data would influence their relationship with the customers. I3 stated: "Showing detailed car data to the customer would increase his/her trust in me." Three interviewees expect the used car market to change if used car dealers become more datadriven. I5 explained: "With trusted data a car can be sold more quickly but you also make less money. " Three interviewed used car dealers, who all have more than 25 years of experience, stated that used car dealer's business processes drastically changed with the emergence of the internet. Looking back on this development, they all believe that their business - and also their selling tasks - will change even more and that access to trusted car data becomes more and more important.

Macaulay [16] and Diez [5] both addressed the problems caused by inefficient processes for different salesrelated activities. The answers given by used car dealers in the interviews show that this problem still exists today. Four interviewees stated that trade relations with geographically distant dealers are being avoided due to inefficiencies. Another inefficiency is lengthy consulting processes associated with indecisive buyers. Three used car dealers reported that these buyers are particularly challenging and none of the interviewees suggested an efficient solution. Another problem - described by three interviewed used car dealers - is the used car dealers' need to bargain with private sellers since they tend to expect a higher price for their car than a dealer is willing to pay. Consequently, private sellers ask different used car dealers for a price offer which leads to low dealer margins when reselling used cars. In order not to 
incur a loss, used car dealers are eventually forced to cut back on their expenses. They often do so by reducing the repair costs of their used cars which leads to poor quality cars. This shows that information asymmetries exist between buyers and sellers of used cars not only exist when used car dealers act as sellers but also when they act as buyers. In this scenario, the private person - who sells the car - knows the condition, major damages and the history of the car (at least the history during the time this person was the owner of the car). When used car dealers happen to buy or trade-in a car which is in a bad condition or which was involved in an accident for a relatively high price, they often resell it to other - less trustworthy - used car dealers instead of doing costly repairs. If they would repair it instead, the price, after adding the repair costs and their usual margin, would be so high that the car would not be salable anymore. The interviewed car dealers stated that they do not care if the other dealer will then sell the car in a bad condition.

According to the European Commission [14], low quality of offered services, in particular warranties, is a big problem. Also in the eyes of five interviewed used car dealers bad quality warranties are a major concern in the used car market nowadays. Four used car dealers explained that used car dealers provide different types of warranties that differ widely in quality, which is problematic as different cars have different weaknesses. However, a good warranty should include those parts of the car which are most likely to break. In addition to that, the exact content of a warrant is often not clear to the buyer. Some used car dealers take advantage of that.

As shown in table 2, based on those problems we defined objectives for the proposed design principles. Objective $\mathrm{A}$ is expected to address problem 1 . Thereby, we aim for a fair market without favoring data access for any dealer. We defined objective B to address problem 2. As the used car business is characterized by enduring sales procedures with many stakeholders involved, our intention is to create a solution that can be used by many different used car dealers without becoming obsolete. Objective $\mathrm{C}$ was defined to address problem 3 . We developed one specific solution for each of the three abstract design principles. These solutions are presented in the next section.

\section{Design}

In this section, we present the three designed prototypes for the interface. For each prototype, we list the main functionalities (tables 3-5) along with an exemplary screenshot of the interface (figures 1-3) and we tell a short story to describe a possible use case.

The Car Dossier Analytics follows the design principle $\mathbf{i}$ and combines trusted data from the Car Dossier with data from a dealer's database to have detailed information about a specific car. Primarily, the Car Dossier Analytics is used to offer access to the car's data to prospective buyers. This prototype was created to achieve objective A. More specifically, by providing data access, this prototype can be used to consult indecisive buyers efficiently by giving them detailed information at the beginning of the sales process. Furthermore, the Car Dossier Analytics enables the dealer to create high-level reports based on sold cars. By that, the Car Dossier Analytics acts as a strategic decision support system that facilitates customer advisory services for used car dealers. Table 3 lists the main functionalities of the Car Dossier Analytics and describes who has access to them: the

Table 2. Current Problems of Used Car Dealers, Objectives and Solutions

\begin{tabular}{|c|c|c|}
\hline Problems & Objectives & Design Principles \\
\hline $\begin{array}{l}1 \text { Insufficient data access for } \\
\text { customer advisory services. }\end{array}$ & $\begin{array}{l}\text { A Strengthen advisory role of used car } \\
\text { dealers. }\end{array}$ & i Analyze trusted car data to strengthen advice giving \\
\hline \multicolumn{3}{|c|}{$\begin{array}{l}\text { "Finding out about vehicle equipment is quite complicated even if the contact persons cooperate." (I6) } \\
\text { "Detailed car data can confuse a buyer. Therefore, it is the dealer's task to explain the data to the customers." (I4) } \\
\text { "Providing information about the car history would be appreciated by the buyers. However, for most of the used cars that we sell, we do not } \\
\text { "My purchase possibilities are limited because I do not know the quality of other dealers' cars." (I9) }\end{array}$} \\
\hline 2 Inefficient processes & B Increase efficiency of their offering. & ii Share trusted car data to improve B2B efficiency \\
\hline \multicolumn{3}{|c|}{$\begin{array}{l}\text { "Consulting buyers who are not yet informed results in an inefficient selling process." (I4) } \\
\text { "If I buy a car from another manufacturer I do not know the car's history." (I3) } \\
\text { "If I see an interesting car from a dealer who is situated on the other side of the country, I do not even look at it because, since I do not know } \\
\text { the car's condition, the expenditure of time would be too large." (I9) } \\
\text { "We do not check the condition of car that was involved in an accident as detailed as other cars. We just sell them to other dealers without fix- } \\
\text { ing the damages." (I5) } \\
\text { "I prefer to sell a bad quality car to another dealer than to do costly repairs. This dealer will probably not repair the car but still I am better off } \\
\text { with that solution as it is not my customers who are angry." (I8) }\end{array}$} \\
\hline 3 Bad quality warranties & C Increase quality of their service offering. & iii Use trusted car data to improve risk-sharing products \\
\hline
\end{tabular}




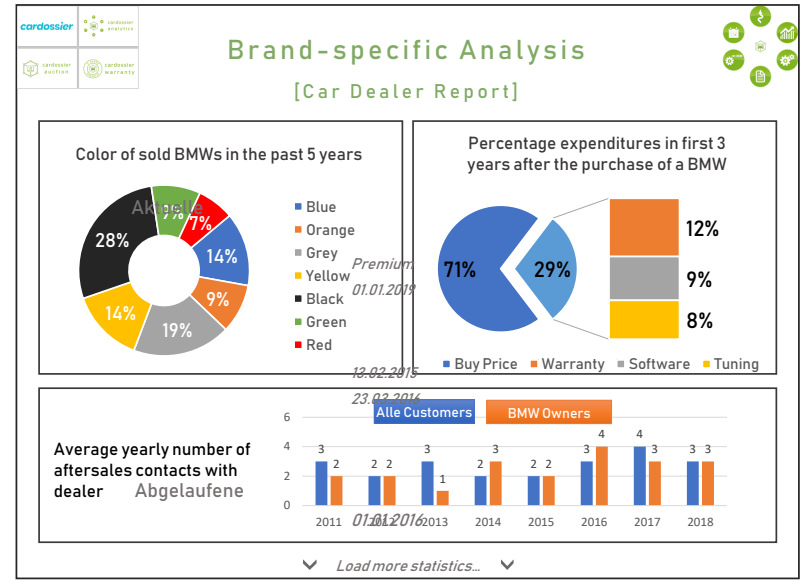

Figure 1. Car Dossier Analytics - Report

Table 3. Car Dossier Analytics

\begin{tabular}{|l|l|}
\hline Functionalities & Access \\
\hline Contact Dealer & Owner \\
\hline Calendar & Dealer \& Owner \\
\hline Ride Analysis & Owner \\
\hline Numbers \& Clues & Dealer \& Owner \\
\hline Reports & Dealer \\
\hline Maintenance & Dealer \& Owner \\
\hline Equipment & Dealer \& Owner \\
\hline Settings & Dealer \\
\hline
\end{tabular}

Use case: Alice (a private buyer) wants to acquire a used car from Bob (a used car dealer). Alice is not sure what kind of car she wants to buy. Thanks to the Car Dossier Analytics Bob can show Alice informative graphics about a specific used car. This includes all events which took place during the entire lifecycle of this car such as all conducted maintenance. At the same time, Bob can show Alice analytics on the model which Alice intends to buy. Seeing these data, e.g. typical usage of such a car, helps her to estimate potentially necessary spending from her side in the future. At the same time, Bob can use the data to make strategic decisions on how to advise his customers.

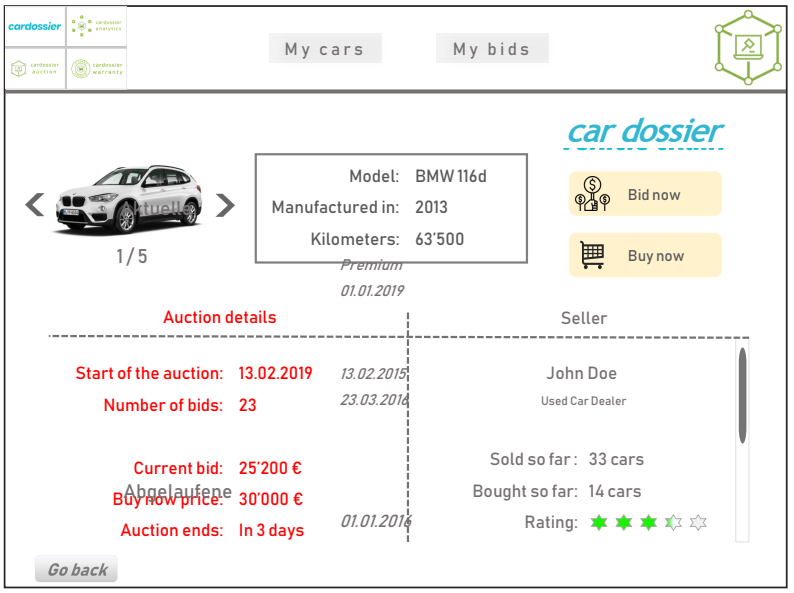

Figure 2. Car Dossier Auction - Bid
Table 4. Car Dossier Auction

\begin{tabular}{|l|l|}
\hline Functionalities & Access \\
\hline Sell Car & Dealer \& Owner \\
\hline Bid & Owner \\
\hline
\end{tabular}

Use case: Bob (a used car dealer) wants to buy a car from John (another used car dealer). Bob and John operate in two different cities far away from each other which is why for Bob it is not feasible to personally inspect the car in question. For this reason, Bob would normally not buy John's car. However, thanks to the Car Dossier Auction, Bob can access detailed information about the car online, based on which he decides whether or not he wants to buy this car. Bob can use this Auction to buy cars not only from dealers but also from private sellers.

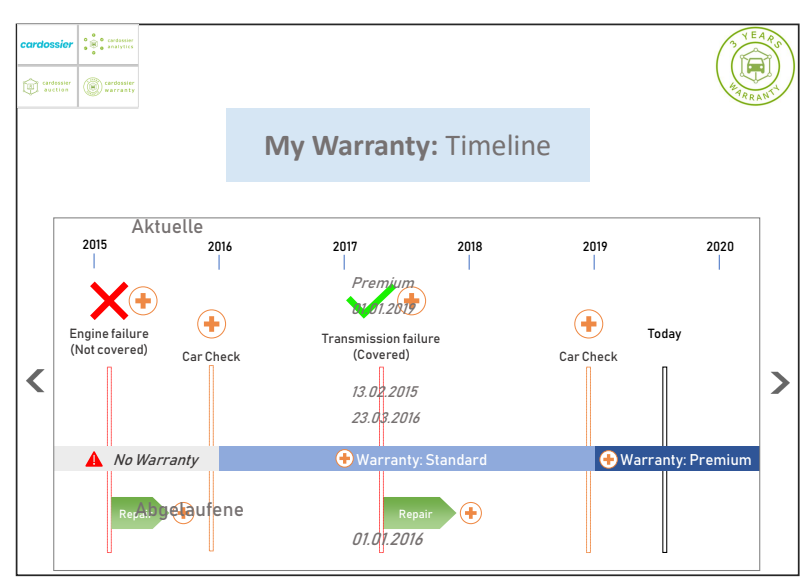

Figure 3. Car Dossier Warranty - Timeline

\section{Table 5. Car Dossier Warranty}

\begin{tabular}{|l|l|}
\hline Functionalities & Access \\
\hline View Warranty & Dealer \& Owner \\
- Timeline & \\
\hline$\quad$ List & Dealer \& Owner \\
\hline Buy Warranty &
\end{tabular}

Use case: Alice's car, which she recently bought from Bob, is damaged. She does not remember exactly what her car's warranty includes. Thanks to the Car Dossier Warranty she can quickly check whether this type of damage is included. Furthermore, she sees the repair as an event in the timeline after it has been done and she can even change her warranty or procure a new one if desired. 
owner is the buyer of the car and the dealer is the dealer who sold the car. The owner can directly contact the dealer in the Car Dossier Analytics. The Calendar gives an overview of all car-related events (e.g., repairs). The Ride Analysis provides information about the last time the vehicle was driven, such as mileage and gasoline consumption. Number \& Clues provide the latest news and fun facts about the model of the car. Reports give dealers the possibility to create reports based on buyers' data (provided buyers give consent to use their data). Figure 1 visualizes a possible dashboard of such a report. Maintenance lists detailed data about carried out maintenance. Equipment lists all components of the car categorized as: standard, supplementary, repair, and tuning. In Settings the owner can configure the Car Dossier Analytics as they wish.

The Car Dossier Auction follows the design principle ii and provides a platform where everyone (whose car is connected to the Car Dossier) can sell their car in just a few clicks. This prototype was built to achieve objective B: It should enable dealers to conduct business with each other despite large geographical distances, it should simplify selling a car, and it should reduce the used car dealer's need to bargain when purchasing used cars. Table 4 lists the main functionalities of the Car Dossier Auction and describes who has access to them. Everyone (private car owners as well as dealers) can sell their car on the Car Dossier Auction platform. However, only dealers can bid for a car on the platform. To sell a car, the duration of the auction, the starting price and (if desired) the buy now price are the only things the seller can define. The bidder can view all cars that are currently available. Figure 2 shows what bidders see when they want to bid for a car. The bidder can click on Car Dossier to access trusted car such as the history, the current condition or pictures of the car.

The Car Dossier Warranty follows the design principle iii and introduces a trusted car warranty to the Car Dossier. This prototype should achieve objective C. More specifically, this prototype should prevent dealers from offering bad warranties, giving car owners the chance to buy or (if they already have one) extend a warranty themselves. The Car Dossier Warranty gives Used Car Dealers the chance to offer tailored warranties. Based on the specific features of a car such as age, condition, mileage history a suitable set of car parts can be included in the warranty. Further, the Car Dossier Warranty enables car owners to see detailed specification of the currently active warranty and a detailed history of past warranties at any time. Table 5 lists the main functionalities of the Car Dossier Warranty and describes who has access to them. The owner and the dealer can view the warranty either as a timeline or in a list. The timeline view is displayed in figure 3 . If the car does not meet the warranty's requirements, the owner can contact the dealer. The owner can also sign a warranty so that the dealer updates the warranty in the Car Dossier.

\section{Evaluation}

According to the questionnaire, all three prototypes follow an easily understandable process, are easy to use, and perform well - in the sense that they contain all relevant functionalities to achieve the intended goals. Most of the interviewed used car dealers rated purpose and intention to use highly for all three prototypes, which indicates that they will be important tools for used car dealers in the future and that most used car dealers would use them. Average NPS of 7.85, 8.00 and 7.30 show that the interviewees had a very good impression of all three use cases. Figure 4 shows a consolidated SWOT analysis from the three prototypes. All prototypes convinced the interviewees with their simplicity and time they could save for the used car dealer. Four interviewees explicitly stated that in the eyes of a used car dealer, simplicity is the most important requirement for a newly introduced application.

Due to its extensive data and many functionalities, the Car Dossier Analytics was reported to be useful for car acquisitions. Nine out of ten interviewees predict a

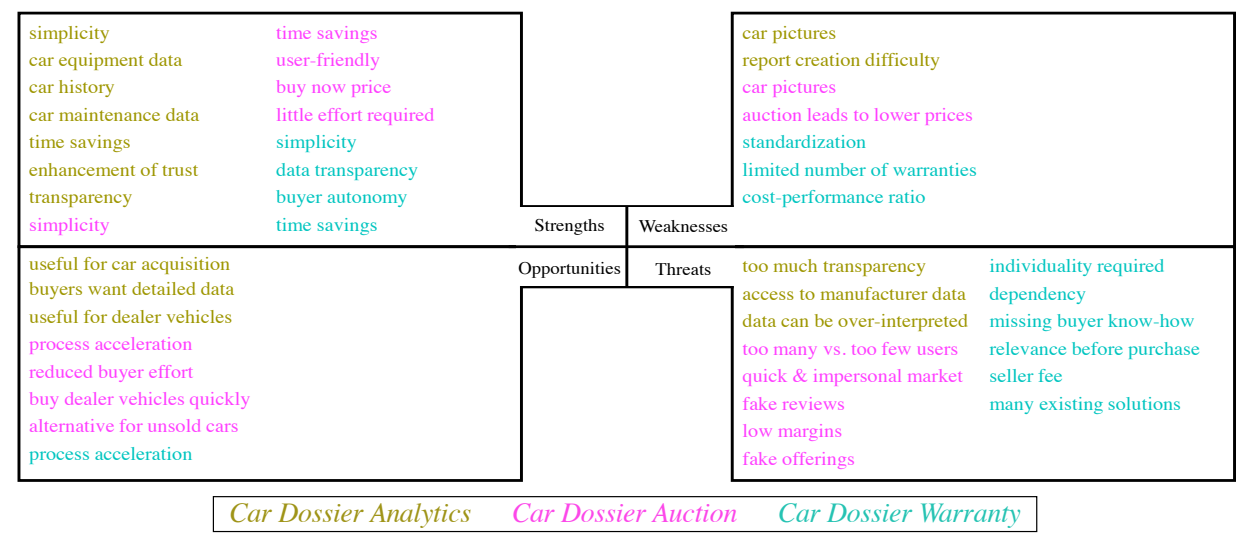

Figure 4. Consolidated SWOT Analysis 
high probability of success for the Car Dossier Analytics. Only one interviewee was skeptical because of the difficulty in accessing the manufacturer's data. Three used car dealers were concerned that the Car Dossier Analytics offers too much transparency. I6 stated: "The more a buyer knows, the lower my margin is." Nine out of ten used car dealers predict a high probability of success for the Car Dossier Analytics. According to the questionnaire, used car dealers are willing to pay an average of $€ 75.35$ for the Car Dossier Analytics per car. A pretty high median of $€ 68.25$ per car shows that there are very few used car dealers who do not see the value in this prototype.

The key opportunities of the Car Dossier Auction are an acceleration of sales processes and reduced effort for the buyer as well as for the seller. The NPS median for the Car Dossier Auction is 8.5, which is 0.5 higher than for the other prototypes. This indicates that used car dealers are most likely to recommend the Car Dossier Auction to a friend. I1 stated: "I would definitely recommend it to a friend, but I would not recommend it to my competitors because I want to be one of just few privileged car dealers to use such a great tool." The interviewees only criticism was that the date a specific picture of the car was taken is not visible in the prototype and that more price transparency might lead to lower car prices. Seven out of ten used car dealers predict a high probability of success for the Car Dossier Auction. In the questionnaire, the Car Dossier Auction was rated the most useful of the three prototypes. On average, used car dealers are willing to pay $€ 109.85$ per car for the Car Dossier Auction, with a median of $€ 68.25$, which is equal to the median of the Car Dossier Analytics.

Improved transparency and buyer autonomy are strengths of the Car Dossier Warranty prototype. According to four interviewees, this prototype will be important in the future since there is some pent-up demand when it comes to warranties in the used car market: "Many used car dealers offer bad warranties." (I11) However, the evaluation showed that our prototype still faces many threats: the required individuality of a warranty, the dependency on established third-party providers, and the negligence of warranties before the purchase of a car were stated the most. In this regard, I8 stated: "Buyers only deal with the warranty when it is already too late." Depending on how high the price for the Car Dossier Warranty will be, the cost-performance ratio might be a weakness. I12 explained: "I am not willing to pay anything [...] because a warranty is something that I think about after I sold a car." The used car dealer's WTP for the Car Dossier Warranty is, on average, $€ 16.80$ per car. A low WTP median of just $€ 0.90$ per car shows that only few used car dealers see the value in this prototype.

\section{Discussion}

Our three prototypes provide concrete examples for the value disciplines introduced by Treacy and Wiersema [41]. As for customer intimacy, the Car Dossier Analytics use case shows how used car dealers can strengthen their advisory role with access to trusted car data. Operational efficiency is instantiated with the Car Dossier Auction use case which demonstrates increased efficiency of used car dealer's offering. For product innovation, the use case of tailored warranties (Car Dossier Warranty) shows how used car dealers can use trusted data to increase the quality of their service offering. These findings are valuable for both researchers and practitioners as they show how used car dealers can use trusted car data to create value.

Our results show that - as stated by Wagner [7] used car sales are still an important contributor to a car dealership's revenues today. Diez's [5] and Neu's [15] statements could not be totally confirmed: Car salespeople do aim for the buyers to trust them on a personal level, but since the used car dealers' business increasingly takes place on the Internet, personal trust in the seller is not sufficient anymore. The interviews showed that nowadays car salespeople need to be able to quickly give the buyer the relevant information without spending too much time on indecisive buyers. Still, our findings coincide with Eckert's [18] assertion that the salespeople are the ones with the biggest influence on the economic success of a used car dealer. For this reason, used car sellers are afraid of losing their bargaining power due to too much transparency which, according to our SWOT analysis, is one of the biggest threats to the Car Dossier Analytics. Even though decentralized solutions - such as the blockchain technology - promises to be disrupting [19], we found that used car dealers do not fear to be replaced by technology in the future but they rather see potential in trusted car data.

Information asymmetries are both a blessing and a curse for used car dealers: While they give them more room for maneuver when selling a used car to an unknowing buyer, they struggle with access to relevant data themselves on a daily basis. Our findings conform with Diez' [5] regarding the fact that not all used car dealers have equal access to data. Used car dealers need considerable time and effort to build their network and then also to find the data they need by asking different persons from their network. Using trusted car data reduces the problem of unequal access to data between different used car dealers and helps all used car dealers to conduct their daily business more efficiently. This yields reduced information asymmetries and thus, all used dealers would have equal access to car data. In this case, used car dealers would be willing to provide their customers access to these data as this can help to build trust 
between a used car dealer and his customers. Hence, information asymmetries from a buyer's perspective, as described by Akerlof [2], are being reduced. Also, lack of trust, one of the biggest problems in the used car market [14], would be reduced.

One of our prototypes, the Car Dossier Analytics, represents an IT artifact that increases transparency and ease of data access for buyers and sellers. The evaluation yielded a positive result which indicates that such a solution would indeed be utilized by used car dealers and that they would be willing to pay for it as it helps them to strengthen their advisory role. This is necessary since buyers often do not have the technical know-how to understand detailed car data. The results of our SWOT analysis further acknowledge that the tool's extensive functionalities - especially the reporting opportunities assist today's sales processes and expand the competences of used car dealers. Our second prototype, the Car Dossier Auction, was rated to be even more helpful for used car dealers. We found that this solution would finally enable used car dealers to conduct business with geographically distant competitors. The evaluation results showed that the Car Dossier Auction would drastically increase the efficiency of sales related processes. For these reasons, the interviewed used car dealers would be willing to spend an average of $€ 109.85$ per car when making use of the Car Dossier Auction. The Car Dossier Warranty intends to contribute to the quality of warranties in the used car market as, according to Akerlof [2], business suffers from bad guarantees. The evaluation of the Car Dossier Warranty revealed that its successful implementation would be more challenging compared to the other use cases. Even though our results coincide with the European Commission's [14] study, regarding the fact that many fraudulent warranties are still being sold today, used car dealers do not intend to change their habits when selling warranties. Following Diez's [5] three critical factors for success, we found that while all our use cases help used car dealers to optimize their processes, they influence neither the profiling of business nor the quality of personnel. However, our findings suggest that, despite not being among Diez's [5] critical factors, a strengthened advisory role, increased efficiency of their offering and increased quality of the service offering are likely to positively influence the success of used car dealers.

\section{Conclusion}

In the introduction, we raised the question of how used car dealers can use trusted car data to create value. Our results provide evidence that by following the abstract design principles we defined, using trusted car data can solve current problems experienced by used car dealers and reduce information asymmetries. We further found that in contrary to used car buyers and private sellers who profit from increased transparency in the market [20], used car dealers fear reduced margins due to too much transparency. Still, used car dealers do not fear to be replaced by technology in the future since the use of a trusted car data platform - e.g., in the form of our three prototypes - creates value for them. For these reasons, used car dealers would be willing to use all three of our prototypes.

According to Diez [5], as well as our own interviews, insufficient data access is one of the major problems facing used car dealers. Our prototypes are able to solve this problem. Furthermore, our three designed prototypes improve the efficiency of several sales related processes. Macaulay [16] and Diez [5] addressed this problem and our interviews clearly showed that used car dealers have difficulties conducting sales related processes efficiently. In this regard, our prototypes create the most value, which is why this is where the biggest potential of a trusted car data platform lies for used car dealer businesses. A centralized platform could not yield the same potentials for used car dealers. Even though decentralized technologies are known for disintermediating trusted third parties [19], our findings indicate that this might not be the case in the used car market. Our results show that usage of trusted car data may rather expand the competences of a used car dealer: They can become more knowledgeable, improve the efficiencies of their processes, and eventually become more data-driven by having access to trusted car data.

We acknowledge the following limitations of this study which also offer directions for future research. First, our study is limited to Western European countries which is why caution is required when generalizing the findings. Therefore, other geographic areas should be further studied. Second, we focus on qualitative rather than quantitative data. Thus, future studies should take a broader approach and acquire quantitative data (e.g. by conducting surveys with used car marketplaces). Third, we used prototypes in a controlled setting for the evaluation and not a finalized system. Testing a complete system in a real-world environment could lead to additional required functionalities of the application. We hope that this study inspires follow-up studies to further research opportunities for trusted car data in the used car market.

\section{References}

[1] E. W. Bond, "A direct test of the 'Lemons' model: The market for used pickup trucks," The American Economic Review, vol. 72, no. 4, pp. 836-840, 1982.

[2] G. A. Akerlof, “The Market for 'Lemons': Quality Uncertainty and the Market Mechanism," Uncertainty in Economics, pp. 235-251, 1978.

[3] K. L. Brousmiche, T. Heno, C. Poulain, A. Dalmieres, and E. B. Hamida, "Digitizing, securing and sharing vehicles life- 
cycle over a consortium blockchain: Lessons learned," in 2018 9th IFIP International Conference on New Technologies, Mobility and Security (NTMS), pp. 1-5, 2018.

[4] L. Zavolokina, G. Miscione, and G. Schwabe, "Buyers of 'lemons': How can a blockchain platform address buyers' needs in the market for 'lemons'?," Electronic Markets, vol. 30, no. 2, pp. 227-239, 2020.

[5] W. Diez, Automobil-Marketing: Navigationssystem für neue Absatzstrategien. MI Wirtschaftsbuch, 2006.

[6] A. Gavazza, A. Lizzeri, and N. Roketskiy, "A Quantitative Analysis of the Used-Car Market," The American Economic Review, vol. 104, no. 11, pp. 3668-3700, 2014.

[7] E. Wagner, Mehr Geld verdienen mit Gebrauchtwagen: Beschaffung, Markenkonzept, Preise. Auto Business Verlag, 2005.

[8] M. Methner, Vertriebssysteme im Automobilhandel: Strategische Möglichkeiten von Hersteller und Importeur zur Gestaltung des Kontakts zum Endkunden. Springer-Verlag, 2002. [9] J. Levin, "Information and the Market for Lemons," $R A N D$ Journal of Economics, pp. 657-666, 2001.

[10] C. Wilson, "The nature of equilibrium in markets with adverse selection," The Bell Journal of Economics, vol. 11, no. 1, pp. 108-130, 1980.

[11] D. Genesove, "Adverse Selection in the Wholesale Used Car Market," Journal of Political Economy, vol. 101, no. 4, pp. 644-665, 1993.

[12] J. R. Peterson and H. S. Schneider, "Adverse selection in the used-car market: evidence from purchase and repair patterns in the Consumer Expenditure Survey," The Rand Journal Of Economics, vol. 45, no. 1, pp. 140-154, 2014.

[13] S. Lades, "Vertrauen der Deutschen in Sicherheitskräfte wächst weiter - Automobilbranche mit starken Verlusten," GFK Verein, Mar. 15, 2017.

[14] European Commission, "Study on the second hand cars market," European Commission, Oct. 01, 2014. https://ec.europa.eu/info/publications/study-second-hand-cars-market_en (accessed Jul. 14, 2019).

[15] M. Neu, Verkaufsmanagement: Professionelle Beratungsund Verkaufsstrategien. BWV Verlag, 2006.

[16] S. Macaulay, Law and the Balance of Power: the Automobile Manufacturers and their Dealers. Russell Sage Foundation, 1966.

[17] M. R. Busse, D. G. Pope, J. C. Pope, and J. Silva-Risso, "Projection bias in the car and housing markets," National Bureau of Economic Research, 2012.

[18] G. Eckert, Die Schlacht um jeden Preis: so gewinnen Sie den Preiskampf im Automobilhandel. Auto Business Verlag, 2000.

[19] M. Swan, Blockchain: Blueprint for a new economy. O’Reilly Media, 2015.

[20] I. Bauer, L. Zavolokina, and G. Schwabe, "Is there a market for trusted car data?," Electronic Markets, vol. 30, no. 2, pp. 211-225, 2020.

[21] A. Penland, D. Shrier, T. Hardjono, and I. WladawskyBerger, "Towards an internet of trusted data: A new framework for identity and data sharing," in Massaschusetts Institute of Technology. Input to he Commission on Enhancing National Cybersecurity, 2016.

[22] A. Parment, Die Zukunft des Autohandels. Wiesbaden: Springer Fachmedien Wiesbaden, 2016.
[23] B. Carson, G. Romanelli, P. Walsh, and A. Zhumaev, "Blockchain beyond the hype: What is the strategic business value?," McKinsey \& Company, 2018.

[24] Z. Zheng, S. Xie, H. Dai, X. Chen, and H. Wang, “An Overview of Blockchain Technology: Architecture, Consensus, and Future Trends," in 2017 IEEE International Congress on Big Data (BigData Congress), pp. 557-564, 2017.

[25] X. Xu et al., "A Taxonomy of Blockchain-Based Systems for Architecture Design," in 2017 IEEE International Conference on Software Architecture (ICSA), pp. 243-252, 2017.

[26] A. R. Hevner, S. T. March, J. Park, and S. Ram, "Design Science in Information Systems Research," MIS Quarterly, vol. No. 1, no. 28, pp. 75-105, 2004.

[27] K. Peffers, T. Tuunanen, M. A. Rothenberger, and S. Chatterjee, "A Design Science Research Methodology for Information Systems Research," Journal of Management Information Systems, vol. 24, no. 3, pp. 45-77, 2007.

[28] J. F. Nunamaker, R. O. Briggs, D. C. Derrick, and G. Schwabe, "The Last Research Mile: Achieving Both Rigor and Relevance in Information Systems Research," Journal of Management Information Systems, vol. 32, no. 3, pp. 10-47, 2015. [29] M. K. Sein, O. Henfridsson, S. Purao, M. Rossi, and R. Lindgren, "Action design research," MIS quarterly, pp. 37-56, 2011.

[30] J. Vom Brocke et al., "Reconstructing the giant: On the importance of rigour in documenting the literature search process.," in ECIS, vol. 9, pp. 2206-2217, 2009.

[31] T. van der Wiele, M. Hesselink, and J. van Iwaarden, "Mystery shopping: A tool to develop insight into customer service provision," Total Quality Management \& Business Excellence, vol. 16, no. 4, pp. 529-541, 2005.

[32] T. Wengraf, Qualitative research interviewing: Biographic narrative and semi-structured methods. Sage, 2001.

[33] J. Saldaña, The coding manual for qualitative researchers. Los Angeles, Calif: Sage, 2009.

[34] C. Sonnenberg and J. Vom Brocke, "Evaluation patterns for design science research artefacts," in European Design Science Symposium, pp. 71-83, 2011.

[35] M. Söllner, A. Hoffmann, H. Hoffmann, A. Wacker, and J. M. Leimeister, "Understanding the formation of trust in IT artifacts," Orlando Florida, USA, 2012.

[36] M. Koufaris and W. Hampton-Sosa, "The development of initial trust in an online company by new customers," Information \& management, vol. 41, no. 3, pp. 377-397, 2004.

[37] A. Bhattacherjee and C. Sanford, "Influence processes for information technology acceptance: An elaboration likelihood model," MIS quarterly, vol. 30, no. 4, pp. 805-825, 2006.

[38] F. F. Reichheld, "The one number you need to grow," Harvard business review, vol. 81, no. 12, pp. 46-55, 2003.

[39] C. Homburg, N. Koschate, and W. D. Hoyer, "Do satisfied customers really pay more? A study of the relationship between customer satisfaction and willingness to pay," Journal of Marketing, vol. 69, no. 2, pp. 84-96, 2005.

[40] H. Shinno, H. Yoshioka, S. Marpaung, and S. Hachiga, "Quantitative SWOT analysis on global competitiveness of machine tool industry," Journal of Engineering Design, vol. 17, pp. 251-258, 2006.

[41] M. Treacy and F. Wiersema, "Customer intimacy and other value disciplines," Harvard business review, vol. 71, no. 1, pp. 84-93, 1993. 